ORIGINAL ARTICLE

\title{
A Delphi study to identify performance indicators for emergency medicine
}

\author{
E Beattie, K Mackway-Jones
}

Emerg Med J 2004;21:47-50

See end of article for authors' affiliations

.....................

Correspondence to: Miss E Beattie, Accident and Emergency Department, Ealing Hospital, Uxbridge, Southall, Middlesex UB1 3HW, UK; ebeattiel@ yahoo.com

\begin{abstract}
Objectives: The aim of this study was to identify performance indicators thought to reflect the quality of patient care in the emergency department.

Methods: A three round accelerated Expert Delphi study was conducted by email or fax. A panel of 33 experts drawn from the fields of emergency medicine, emergency nursing, professional service users, and patients were consulted. Participants were initially asked to propose performance indicators that reflected the quality of care given in the emergency department setting in the United Kingdom. In the second round these proposals were collated and scored using a 9 point Likert scale; those that had not reached consensus were returned for reconsideration in the light of group opinion. Those statements reaching a pre-defined consensus were identified.

Results: 224 performance indicators were proposed. Altogether 36 indicators reached consensus reflecting good departmental performance after round three; 24 of these were process measures.

Conclusions: 36 potential indicators of good quality of care in the emergency department in the UK have been identified.
\end{abstract}

W ithin the United Kingdom the specialty of emergency medicine is facing pressures from increasing patient numbers ${ }^{1}$ and the need to reduce waiting times. ${ }^{23}$ At the same time the medical profession is being urged to be more accountable and outcome indicators are being developed across a broad range of specialties. ${ }^{4}$ These indicators can have many purposes ranging from informing patients of the quality of service they can expect from their local hospital to allowing purchasers of health care to see that they are getting value for money.

The concept of measuring performance in health care is not new. Ernest Codman, a Boston surgeon, was recording the outcomes of his care and disseminating the information as early as 1914. ${ }^{5}$ Later Donabedian proposed the division of health care into structure, process, and outcome, which are causally linked. ${ }^{6}$

- Structure-the human, physical and financial resources available to provide health care

- Process-the care or health service provided to the patient

- Outcome-the resulting effect on the health of the patient or population

Aspects of each of these can be measured or quantified although there is an emphasis on measuring outcomes- the end results of patient care. Outcome indicators are aggregated statistical measurements that describe the outcomes of health care for a group of patients or a whole population. ${ }^{7}$ Examples of outcomes measured include mortality, morbidity, physiological parameters or more subjective patient based assessments of health. Outcome indicators are rare in emergency medicine. Performance indicators measure quality of care and may encompass process, outcome, and effectiveness. ${ }^{7}$ The Joint Commission on Accreditation of Healthcare Organisations in the United States uses measures of process such as the timing of computed tomography in head injury as proxies for outcome when evaluating the quality of care in emergency departments. ${ }^{8}$ An example of performance assessment that encompasses emergency department care is the United Kingdom Trauma Audit and Research Network-a large database recording the outcome of patient care in trauma in terms of mortality. ${ }^{9}$ This links outcome with both structure and process.

The only current recorded indicator that directly addresses emergency department performance relates to waiting time. ${ }^{10}$ Although emergency departments do make a contribution to other NHS indicators such as mortality from skull fractures and suicide rates, it is difficult to quantify. There is a pressing need to develop indicators that reflect the quality of care delivered to the whole range of patients presenting to the emergency department.

The aim of this Delphi study was to identify aspects of practice thought to be indicative of the quality of emergency department care.

\section{METHODS}

An accelerated Delphi study was conducted between January and March 2001 using a panel of 33 experts. These included emergency physicians from a broad range of departments, senior emergency nurses, inpatient specialists with an interest in emergency care or outcomes research, and a patients' representative from the Community Health Council. Thus a wide range of views was represented-including those of service providers, professional service users, and patients. The views of all participating experts were given equal weight. A list of the members of the Delphi panel is given in the appendix (available to view on the journal web site, http://www.emjonline.com/supplemental).

The first round of the Delphi asked the panellists to consider the aspects of emergency department care that might represent the quality of patient management. They were asked to propose indicators under the broad specialty subheadings shown in the box.

The replies were collated into a series of proposed indicators/statements covering a wide range of topics. In the second round these statements were returned to the panel members in the form of a series of statements about which they were required to express their level of agreement with the use of the proposed measure as a performance indicator. This was done using a 9 point Likert Scale. ${ }^{11}$ After 
Subheadings for proposed indicators in round

one

- Surgery/orthopaedics/trauma

- Paediatrics

- Psychiatry

- Anaesthesia/analgesia

- Obstetrics and gynaecology/ENT/ophthalmology

- Primary care

- Minor injury

- Radiology/imaging/investigations

- Cardiac arrest

- Bereavement

- Major incidents

- Other

this round the results were analysed for frequency of response using the SPSS for Windows statistical package. Statements that had reached consensus as either good or bad indicators of quality of care were identified. Positive consensus was defined as $80 \%$ or more of respondents scoring 6 and above. Negative consensus was defined as $80 \%$ or more of respondents scoring 4 and below. In the third round the remaining statements were returned to the panellists in a similar format to round two. In addition the scores from round two were summarised and the respondent's score was underlined as shown in figure 1. This allowed group members to change their response in the light of group opinion. Comments or concerns that had been expressed by panellists in the second round were also added to the round three questionnaires.

\section{RESULTS}

Of the 33 panellists, 28 completed round one, 31 round two, and 30 round three. Three of the 31 replies in round two were received after analysis so their responses were not included until the completion of round three. Round one produced a series of 224 statements that were then returned to the panellists. After round two 43 indicators had reached consensus as either good or bad indicators, and were removed from the process. A further 13 indicators reached consensus after round three. The 36 measures reaching consensus as having good potential for use as departmental performance indicators are shown in table 1 with the 20 measures thought to be poor performance indicators in table 2 . The remaining statements are not presented here.

\section{DISCUSSION}

This study has identified potential indicators thought to reflect the quality of care given to the whole range of patients presenting to emergency departments. These can provide a starting point for further research and implementation. With adequate input of resources they could be incorporated into a national framework for quality control. Clearly, while healthcare providers are being urged to measure outcomes there are problems assessing the outcomes of emergency care. One current performance indicator for emergency departments relates to waiting times-a measure of process. ${ }^{10}$ In this study "time to be seen" and "total time in the department for patients with minor injury" were thought to represent good departmental performance whereas "total time in the department for admitted patients" depends on many other factors and consensus was not reached. Health Services Accreditation published performance indicators for accident and emergency services in 1997 and some of the indicators from this Delphi were similar to those best practice standards. ${ }^{16}$ These need to be developed and disseminated as measurable standards that are suitable for audit.

The panellists were chosen to represent a large number of viewpoints and the use of the Delphi technique allowed the panel to express their views anonymously. In this way consensus could be sought without prejudice and interpersonal relationships introducing bias. Panellists were also able to change their minds once they had seen the spread of opinion from the rest of the group and any relevant comments. Nevertheless, the Delphi process does have some limitations. ${ }^{12}$ The selection of the panel depended on the subjective opinion of the researchers and the availability of the experts within the allocated time period. The wide variety of indicators proposed in round one meant that the focus necessarily had to change from outcome indicators to performance indicators. This was felt to be a reflection of the difficulty in measuring outcomes within emergency medicine. Although 224 indicators were proposed in round one it is possible that important issues have been overlooked. Consensus as defined above does not mean agreement.

Although initially aiming to identify outcome indicators for emergency medicine, the proposed indicators in the first round reflected structure, process, and outcome. Most measured processes occurring within the emergency department. This may be because the specialty is process driven, with the timings of procedures being related to the urgency of the presentation. There are many problems with the assessment of outcomes in emergency medicine. For many patients the care received in the emergency department constitutes only a small proportion of their overall health care with other specialists responsible for their ongoing management. For these patients the timeliness and appropriateness of the diagnostic and therapeutic processes are the most important aspects of emergency department care. The outcomes of these processes may not be apparent when the patient leaves the department and it is not clear when the outcomes of emergency care for these patients should be assessed. For many other patients, treated solely by the emergency department, the outcome of their episode of care is again unclear. Only a small proportion of these are followed up in review or fracture clinic and the outcome for

\begin{tabular}{|c|c|c|c|c|c|c|c|c|c|c|c|}
\hline & \multicolumn{9}{|c|}{$\begin{array}{l}\text { Potential for use as departmental } \\
\text { performance indicator }\end{array}$} & \multirow{3}{*}{ Comments } & \multirow{5}{*}{$\begin{array}{l}\text { Figure } 1 \text { Example of the format of the } \\
\text { round three questionnaire (the numbers } \\
\text { represent the number of respondents } \\
\text { agreeing at each level. This participant } \\
\text { had scored } 8 \text { in round two and on } \\
\text { seeing the group opinion and } \\
\text { comments altered his score to 9). }\end{array}$} \\
\hline & Poor & & & & & & & & Ment & & \\
\hline & 1 & 2 & 3 & 4 & 5 & 6 & 7 & 8 & 9 & & \\
\hline \multirow{2}{*}{$\begin{array}{l}\text { Time from arrival to } \\
\text { fluids in patients } \\
\text { with suspected } \\
\text { diabetic } \\
\text { ketoacidosis }\end{array}$} & & & & & & & & & $\sqrt{ }$ & \multirow{2}{*}{$\begin{array}{l}\text { Uncommon } \\
\text { Does a small delay } \\
\text { matter? } \\
\text { How do we define } \\
\text { suspected? }\end{array}$} & \\
\hline & 1 & 3 & 0 & 3 & 3 & 2 & 2 & $\underline{4}$ & 5 & & \\
\hline
\end{tabular}




\begin{tabular}{|c|c|}
\hline Patient group & Performance indicator \\
\hline Medicine & $\begin{array}{l}\text { Time from arrival to ECG patient group ?in cardiac chest pain(P). Door to } \\
\text { needle time for thrombolysis(P). Proportion of patients with myocardial } \\
\text { infarction given aspirin(P). Time to first nebuliser in acute asthma(P). } \\
\text { Proportion of patients with asthma whose care adheres to British Thoracic } \\
\text { Society guidelines }(\mathbf{P}) \text {. Time to antibiotics in suspected meningitis }(\mathbf{P}) \text {. Time to } \\
\text { see doctor for landmark presenting complaint( }(\mathbf{P}) \text { (complaint to be defined } \\
\text { later). Ability to demonstrate grading of asthma by peak flows and oxygen } \\
\text { saturation(P). Ability to demonstrate management of paracetamol overdose } \\
\text { as per guidelines }(\mathbf{P}) \text {. }\end{array}$ \\
\hline Surgery/orthopaedics/trauma & $\begin{array}{l}\text { Time to analgesia in clinical fractures(P). Proportion of trauma teams led by } \\
\text { ATLS provider(S). Proportion of resus cases treated by a consultant(S). } \\
\text { Proportion of resus cases treated by an SHO alone(S) }\end{array}$ \\
\hline Paediatrics & $\begin{array}{l}\text { Time to antibiotics in children with suspected meningitis(P). Level of } \\
\text { adherence to British Thoracic Society guidelines in children with asthma(P). } \\
\text { Time to antipyretic in children with temp }>38.5 \text { if not given in preceding six } \\
\text { hours(P). Availability of paediatric cardiac arrest team(S) }\end{array}$ \\
\hline Psychiatry & Time from referral to psychiatric opinion $(\mathbf{P})$ \\
\hline Primary care & $\begin{array}{l}\text { Proportion of deaths in which the GP is notified(P). Proportion of GP letters } \\
\text { sent within five working days }(\mathbf{P})\end{array}$ \\
\hline Ophthalmology/ ENT & $\begin{array}{l}\text { Proportion of patients with eye problems who have their visual acuity } \\
\text { recorded(P). }\end{array}$ \\
\hline Analgesia/anaesthesia & $\begin{array}{l}\text { Proportion of patients with pain assessed at triage }(\mathbf{P}) \text {. Ability to provide } \\
\text { evidence of ongoing pain assessment }(\mathbf{P}) \text {. Ability of triage nurses to prescribe } \\
\text { analgesia(P). Time to analgesia in patients with fractures neck of femur }(\mathbf{P}) \text {. } \\
\text { Proportion of intubated patients in which end tidal carbon dioxide is } \\
\text { monitored(P). }\end{array}$ \\
\hline Minor injury & $\begin{array}{l}\text { Proportion of patients with wounds who have tetanus status ascertained and } \\
\text { receive appropriate antitetanus treatment( }(\mathrm{P}) \text {. Total time spent in department } \\
\text { by patients with minor injury }(\mathrm{P})\end{array}$ \\
\hline Imaging/investigations & $\begin{array}{l}\text { Percentage of missed significant abnormalities (significant = patient recalled } \\
\text { or treatment changed)(O). Availability of CT } 24 \text { hours per day }(\mathbf{S}) \text {. } \\
\text { Availability of image linking to nearest neurosurgical centre(S) }\end{array}$ \\
\hline Cardiac arrest & $\begin{array}{l}\text { Proportion of teams led by an ALS provider(S). Survival rates from cardiac } \\
\text { arrests in the emergency department(-) }\end{array}$ \\
\hline Bereavement & $\begin{array}{l}\text { Availability of appropriate relatives room(S). Access to out of hours viewing } \\
\text { of the deceased(S). }\end{array}$ \\
\hline Other & Availability of middle grade cover 24 hours per day $(\mathbf{S})$ \\
\hline
\end{tabular}

the others is usually unknown. The lack of data collection in many departments increases this problem. It must be remembered that from the perspective of both the patient and other healthcare providers, satisfaction with the processes of care should be considered an outcome. This was emphasised in the replies from the representative of the Community Health Council.

Two of the 36 indicators reaching positive consensus in this study were thought by the authors to be direct measures of outcome. One of these proposed that we should assess the survival rate from cardiac arrests within the emergency department using the Utstein criteria. ${ }^{13}$ Survival from out of hospital arrests is evaluated in this way in some regions by the ambulance service. Indicators reflecting the structure of emergency departments, including staffing levels also reached consensus. Many of these have been considered elsewhere. $^{14} 15$

Many of the indicators reaching consensus as a poor reflection of the quality of patient care are not under the direct control of emergency medicine. These include the

Table 2 Proposals reaching consensus as poor indicators of quality of patient care

\begin{tabular}{|c|c|}
\hline Patient group & Performance indicator \\
\hline Surgery & Open reduction rate for fractures \\
\hline Medicine & $\begin{array}{l}\text { Proportion of deliberate self harm patients receiving timely gastric } \\
\text { decontamination. Length of stay in the department for patients with DVT }\end{array}$ \\
\hline Psychiatry & $\begin{array}{l}\text { Proportion of deliberate self harm patients already under the care of the } \\
\text { psychiatrists. Attendance rates for frequent attenders }\end{array}$ \\
\hline Primary care & $\begin{array}{l}\text { Proportion of patients sent by their GP. Proportion of patients for whom the GP } \\
\text { would be more appropriate. Proportion of patients who saw their GP first. } \\
\text { Assessment of level of inappropriate attenders }\end{array}$ \\
\hline Minor injury & Number of pretibial lacerations requiring grafting \\
\hline Ophthalmology/ENT, etc & DNA rate of referred patients to outpatient clinics. Referral rate per specialty \\
\hline Analgesia/anaesthesia & Proportion of patients offered patient controlled analgesia \\
\hline Imaging/investigations & Proportion of negative radiographs. Proportion of negative $C T$ scans \\
\hline Cardiac arrest & $\begin{array}{l}\text { Time from cardiac arrest to presentation at A\&E. Survival rates for out of hospital } \\
\text { cardiac arrests }\end{array}$ \\
\hline Major incident & Proportion of patients not receiving a debriefing after a major incident \\
\hline Other & $\begin{array}{l}\text { Proportion of patients admitted to ITU from A\&E. Availability of cross boundary } \\
\text { agreements with neighbouring trusts. Rate of transfer of patients from the } \\
\text { department }\end{array}$ \\
\hline
\end{tabular}


"proportion of patients sent by their $\mathrm{GP}^{\prime}$ and "time from cardiac arrest to presentation at A\&E". Although these may represent important quality issues for other healthcare providers, they were thought not to be relevant to care in the emergency department. Others, such as the proportion of patients admitted to the intensive care unit from the emergency department were highly case mix dependent.

The results of this study can only be used as a basis for further work. Before any performance indicator can be adopted it needs to be clearly defined, tested for reliability (the ability to give repeatable results), validity (the degree to which the measure reflects actual performance), and responsiveness (the ability to detect a significant change in performance). A widespread accurate system for data collection also needs to be in place. Significant investment in the process of continuous quality monitoring is required for this to occur. More practically, many of these measures could be audited locally, regionally, or even nationally.

This Delphi study provides a starting point for the development of indicators within the specialty of emergency medicine. It has identified areas where further research is needed to explore the outcomes of emergency care and to link measurable processes with these outcomes. This is essential to define the role of emergency departments and to monitor the standard of care from within the specialty.

\section{CONTRIBUTORS}

E Beattie coordinated the project undertook the analysis and wrote the first draft of the paper. K Mackway-Jones initiated the study, identified the panel members and contributed to data interpretation and the subsequent drafting of the paper.

\section{ACKNOWLEDGEMENTS}

The authors would like to thank Mr Mike Clancy and Professor Andrew Long of Salford University for their support and advice.

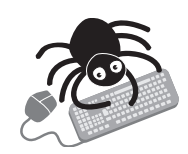

The appendix is available to view on the journal web site (http://www.emjonline.com/supplemental)

\section{Authors' affiliations}

E Beattie, Accident and Emergency Department, St Mary's Hospital, London, UK

K Mackway-Jones, Department of Emergency Medicine, Manchester Royal Infirmary, Manchester, UK

Funding: this research was funded by a research grant from the Faculty of Accident and Emergency Medicine.

Conflicts of interest: none declared.

\section{REFERENCES}

1 Audit Commission for Local Authorities in England and Wales. By accident or design: improving A\&E services in England and Wales. London: Audit Commission, 1996.

2 Department of Health. The NHS Plan-A plan for investment. A plan for reform. London: Department of Health, 2000.

3 Department of Health. Reforming emergency care. London: Department of Health, 2001.

4 Cleary R, Amess M, Coles J. Phase 3 outcome indicators - results from a series of pilot studies. CASPE Research, September 1999.

5 Donabedian A. The end results of healthcare: Ernest Codman's contribution to quality assessment and beyond. Milbank Q 1989;67:233-56.

6 Donabedian A. Evaluating the quality of medical care. Milbank Memorial Fund Q 1966;44:166-200.

7 Boyce N, McNeil J, Graves D, et al. Quality and outcome indicators for acute healthcare services. http://www.health.gov.au/pq/bho/1997/v3nl/ indicat.htm (accessed Nov 2003).

8 National Quality Measures Clearinghouse. http://www.ahcpr.gov/qual/ conquest.htm (accessed Jan 2001).

9 Lecky F, Woodford M, Yates DW. Trends in trauma care in England and Wales 1989-97. UK Trauma Audit and Research Network. Lancet 2000;355:1771-5.

10 NHS Executive. Quality and performance in the NHS: NHS performance indicators. London: Department of Health, 2000.

11 Likert A. A technique for the measurement of attitudes. Methods Psychol (Frankfurt) 1932;22:25.

12 Carley SD, Mackway-Jones K, Donnan S. Delphi Study into planning for care of children in major incidents. Arch Dis Child 1999;80:406-9.

13 Cummins RO, Chamberlain DA, Abramson NS, et al. Recommended guidelines for uniform reporting of data from out of hospital cardiac arrest: the Utstein style. Task force of the European Resuscitation Council, Americal Heart Association, Heart and Stroke Foundation of Canada and the Australian Resuscitation Council. Resuscitation 1991;22:1-26.

14 Working Group of the British Association for Accident and Emergency Medicine and the Royal College of Nursing. Bereavement care in A\&E departments. London: BAEM/RCN, 1995.

15 Royal College of Paediatrics and Child Health. Accident and emergency services for children. London: RCPCH, 1999.

16 Reference withdrawn. 